Pidhaina Vira. Effects of fitness programs with aquatics elements on physical condition of 16-17 year-old males. Pedagogy and Psychology of Sport. 2019;5(2):209-219. elSSN 2450-6605. DOI http://dx.doi.org/10.12775/PPS.2019.05.02.002

http://apcz.umk.pl/czasopisma/index.php/PPS/article/view/PPS.2019.05.02.002

https://zenodo.org/record/4254156

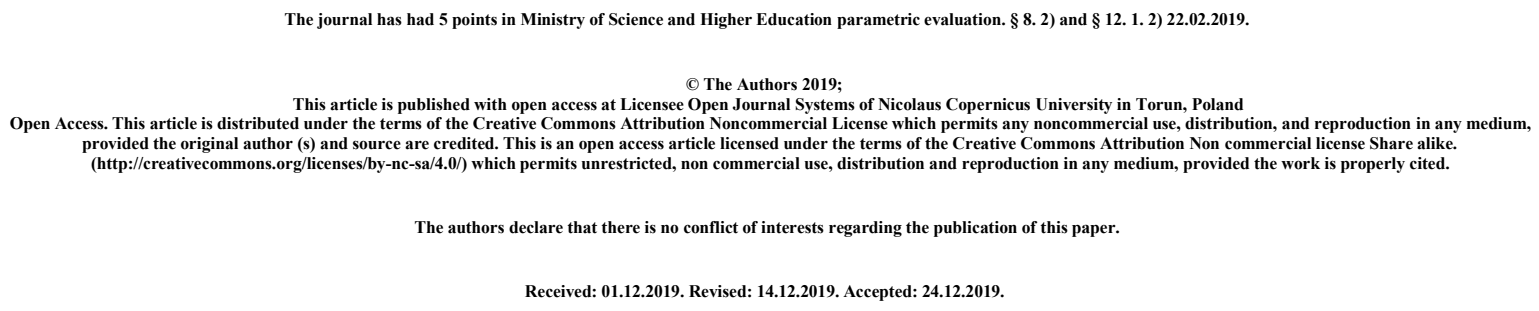

EFFECTS OF FITNESS PROGRAMS WITH AQUATICS ELEMENTS ON PHYSICAL CONDITION OF 16-17 YEAR-OLD MALES

\title{
Vira Pidhaina
}

National University of Ukraine on Physical Education and Sport, Kyiv, Ukraine

\begin{abstract}
The article identifies the impact of an aquatics fitness program on the physical condition of 16-17-year-old males. Objective. The study was aimed at assessing the effects of the fitness program with aquatics elements on physical condition of 16-17 year-old males. Methods and organization of the study. The following methods were used: analysis and generalization of special scientific and methodological literature; pedagogical, sociological, anthropometric, and physiological methods; and the methods of mathematical statistics. To assess physical health, Apanasenko's method for somatic health express assessment was used. The level of physical fitness of young men was assessed according to the Krutsevich's method. The Ruffier, Robinson, Skibinsky, Stange, and Genche indices were used to assess the functional status of the cardiorespiratory system. The program lasted for 9 months with workouts done three times a week. The program included three stages: preparatory (10-12 weeks), main (16-18 weeks), and final (14-16 weeks) ones. The study involved 48 males aged
\end{abstract}


16-17 years. Results of the study. After the experiment, significant $(p<0.05)$ changes were found in the morpho-functional status of 16-year-old men including body weight, heart rate, lung vital capacity, Stange and Genche tests, Ruffier, Skibinsky, and Robinson indices, and vital capacity-to-body weight ratio. In 17-year-old men, the changes in Robinson, Skibinsky, and Quetelet indices, as well as in wrist dynamometry and strength index were found. The results of Ruffier test indicated improvements in physical performance and physical fitness of young men. The physical health of most young men aged 16-17 was improved to the 'safe' level. Conclusions. The effectiveness of the aquatics program was proved. Significant changes were found to occur in the following indicators of physical condition of young men: physical fitness, physical health, work capacity, and morphofunctional condition.

Key words: program, effectiveness, aquatics, young males, rowing, physical condition.

Introduction. At the current stage of development of modern society, it is unacceptable limiting the guys 16-17 years old physical activity to physical education lessons. Physical Education lesson for compensates an average of 11\%, and maximum (at high lesson density) $40 \%$ of the required daily number of locomotions. Even daily physical education lessons are not able to make up for the lack of physical activity. Motor activity in order age about $15-24 \%$ percent daily is satisfied by their spontaneous movements. However, spontaneous movements combined with physical activity performed in the lessons may not fully satisfy the high school students' need for physical activity. The daily amount of physical activity should be at least 2 hours, and weekly at least 14 hours $[1,5,7]$.

Cardiovascular and respiratory systems are improved by maintaining proper motor activity, the musculoskeletal system is strengthened, nervous system activities are regulated and many other physiological processes. It is established that physical exercises are able to increase the body's resistance to adverse environmental factors. Physical activities make it possible to support the physical health of the younger generation effectively. Physical education and recreation are an important factor in maintaining and restoring the health of people, comprehensive development of their physical and spiritual forces [2, 3, 4]. 
Aquarecreation is a means of active rest, an important factor in the prevention of diseases and functional disorders [14].

Analysis of recent research and publications. At the current stage of development of general secondary education in Ukraine, an important strategic task of reforming its content is the need to promote the proper development of physical and mental health of youth, education of schoolchildren, determining the main priorities of a healthy lifestyle and ways of their implementation [16]. However, according to many authors, there is a negative tendency for increase in the number of high school students with low and below average levels of physical health $[14,15,17]$. The vast majority of young men have a low level of physical fitness and they are not able to meet school standards for positive evaluations $[16,18]$. One of the socially significant causes of this phenomenon is a decrease in motor activity of the modern high school student - a decrease in the level of motor activity and an increase in the tendency to mental stress $[6,8,9]$.

Despite the considerable scientific and methodological work, the implementation of physical and recreational activities in secondary schools today has not developed as a single integrated system. One of the reasons for this is the lack of regular systematic reliable and objective information on the dynamics of adolescent health and psychophysiological status $[11,13,16]$.

According to many authors, one of the main components of managing the process of physical education is pedagogical control of the students' physical condition. Studies have shown that quantitative assessment of the level of physical condition is associated with the incidence of youth. Thus, in mass studies of the population it was found that the incidence increases in parallel with the decrease in the level of physical condition $[10,12]$. In contemporary society intensive search for innovative means of increasing the level of physical activity is being conducted. According to many scientists, the possibility of solving this problem is related with the usage of innovative technologies [15, 16]. However, the issue of increasing motivated involvement in youth motor activity is not sufficiently studied, and existing programs do not cover the full range of the issue under study, which makes the research relevant.

The aim of the study was to assess the effects of the fitness program with aquatics elements on physical condition of 16-17-year-old males.

Research Methods: To achieve this objective, a set of complementary general scientific and specific research methods. The analysis of the scientific and methodological literature was carried out with the aim of theoretical substantiation of the object of research, 
as well as generalization of scientific approaches to the organization of physical-fitness activity of young men of the upper classes.

Students' health was assessed on the basis of generally accepted criteria for individual health assessment. In determining the most appropriate health assessment methodology, the study preferred the most accessible, informative, non-invasive, and enabling a large group of children to be reached in a short period of time. Therefore, the study of physical health was conducted by the express method of assessing the level of somatic health G. L Apanasenko. Anthropometry indicators (body length, body weight, lung capacity, wrist dynamometry) and the state of the cardiovascular system are the basis for the method of quantitative rapid assessment of the level of physical health. Measurement of lung capacity was performed using a dry spirometer according to the conventional method. Studies of the muscle strength of the hands were carried out using a wrist dynamometer. The functional state of the body's systems was evaluated using the indexes: Ruffier, Robinson and others, which characterize the work of the cardiorespiratory, autonomic nervous systems. To determine the incidence, were used the International Classifier of Diseases 10th Revision, 2018. It is a document developed by the World Health Organization and used as a leading statistical and classification framework in the health care system. Assessment of the level of physical fitness was carried out according to the method of T. Krutsevich, (2006). Based on the test results, an evaluation of the obtained indicators was carried out. The index method was used for this purpose. A positive feature of the method is the consideration of individual indices of physical development (weight and body height). The level of physical fitness was assessed based on five indicators: strength, speed, strength, life index, endurance index and Ruffier index.

The systematization of the material and the initial mathematical processing were performed by using the Microsoft®Excel 2010 tables. Statistical analysis methods were used in the study using STATISTICA 8.0. The t-Student, Wilcoxon criteria were used to assess the significance of the difference between the indicators.

The study was organized and conducted on the basis of children's and youth sports rowing schools "Burevistnuk" and "Slavytich". The pedagogical experiment was attended by young men 16-17 years (48 people) who were not in the sports groups, but were in the group of the first year of initial training. Experimental-research work was conducted on the basis of Children's and youth sports schools of the academic rowing "Burevistnuk" and "Slavytich", Kiev. The practical work included a conversation with a doctor, a study of the health status of young men on the basis of medical records and testing. 
Results of the study and discussion. Respiratory syndrome (47.84\%) was predominant in the structure of diseases of students 16-17 years (48 boys). In the second place were diseases of the digestive system - 23\%, impaired nervous system was $8.7 \%$. Thyroid enlargement of grade I and II was found in $21.6 \%$ of the surveyed. Pathology of the cardiovascular system was found in $11.3 \%$ of young men. In addition, changes were found from other organs and systems: chronic rhinitis - in 16.64\% of boys; chronic tonsillitis $14.56 \%$, respectively; The majority of surveyed high school students had one or more abnormal abnormalities. An ascertaining experiment convincingly showed that most students are predominantly unhealthy lifestyles, and a small number of boys believe that they adhere to healthy lifestyles. Violations of the main indicators are due to both learning overload and the irrational use of free time.

Comparing indicators of functional status and fitness with morbidity, it can be noted that there is a direct link - the lower the levels, the lower the level of functional status and vice versa. Students who more or less systematically attend physical education lessons are less likely to suffer and have significantly fewer functional abnormalities. The obtained factual material indicates that measures should be developed and implemented aimed at rationally organized physical health classes with relatively new means of physical activity. This way of physical recreational leisure can serve our program of employment with the elements of water recreation (Fig. 1). After conducting the pedagogical experiment, the indicators of the functional state of high school students were significantly improved (Table $1)$.

The preparatory stage involved the involvement of young men in systematic physical and health classes with elements of water recreation during leisure. During the first stage, were used educational methods that were aimed at shaping the consciousness of the youth: story, explanation, conversation, suggestion, coaching, personal example. A characteristic feature of the initial phase of the study was the holding of three aquatic recreational activities during the week. 


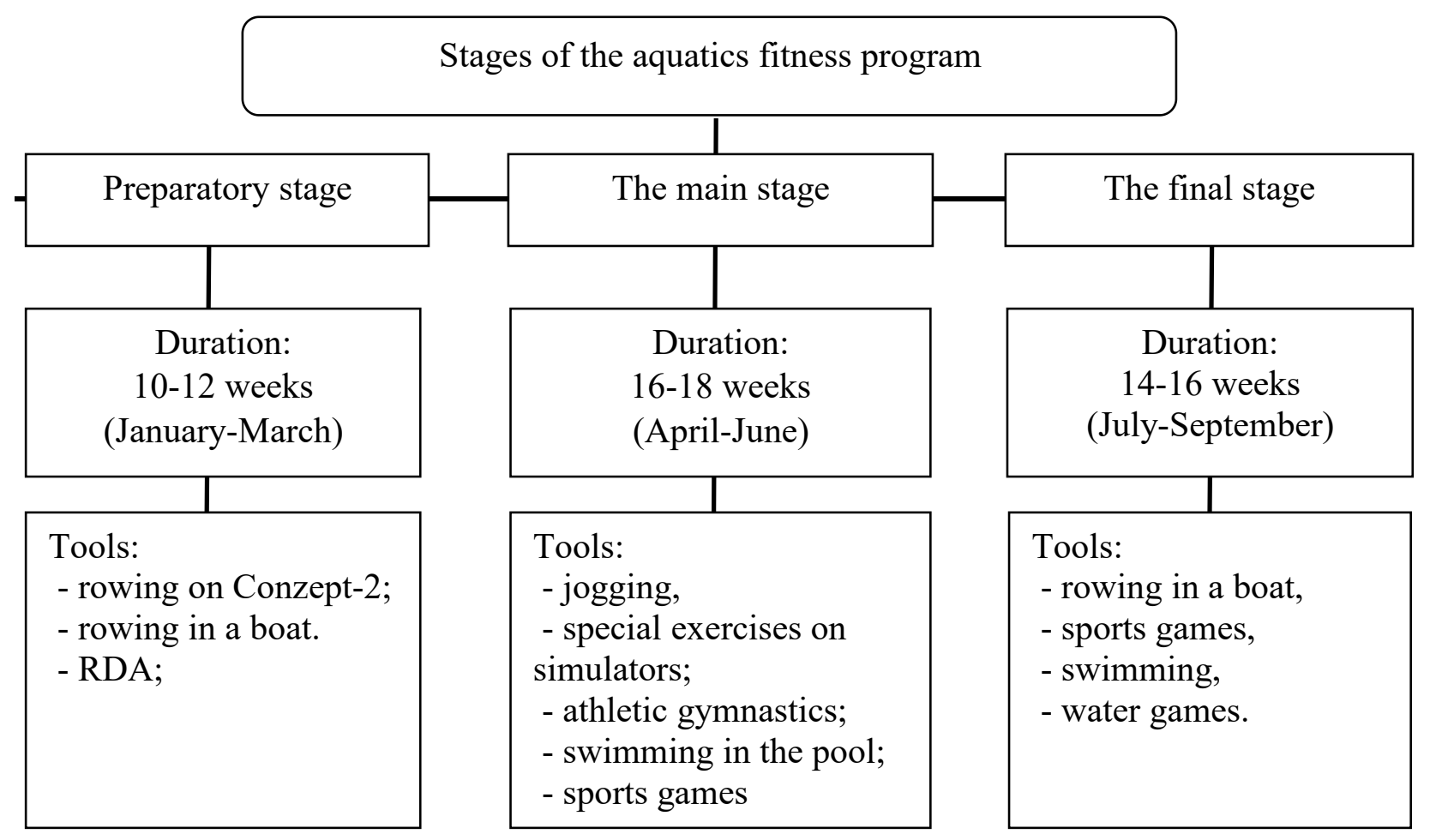

Fig. 1 Features of the program with elements of water recreation

The purpose of the main stage was the organization of fitness program and the formation boys' behavior in leisure. Elements of other recreation are added to the basic assets used in the lesson. The result of the lessons was the formation of positive motivation among high school students to systematically attend physical education classes with elements of water recreation, forming a sustainable interest in their own health. The second stage was aimed at consolidating the knowledge, skills and health promotion skills acquired by young men in the first stage of the pedagogical experiment. Among the variety of means used at this stage, the priority were the educational methods of stimulation and motivation: competition.

The final stage involved determining the final level of physical health and fitness. The peculiarity of this stage was that it took place in the summer, the frequency of classes was three times a week, lasting two hours each. 
Table 1

Dynamics of indicators of functional status of the studied youth groups

before and after the experiment $(x \pm S)$

\begin{tabular}{|c|c|c|c|c|}
\hline \multirow{3}{*}{ Indexes } & \multicolumn{2}{|c|}{16 years $(n=24)$} & \multicolumn{2}{|c|}{17 years $(n=24)$} \\
\hline & To & After & To & After \\
\hline & $x \pm S$ & $x \pm S$ & $x \pm S$ & $x \pm S$ \\
\hline $\begin{array}{l}\text { Heart rate, beats per } \\
\text { minute }-1\end{array}$ & $76,42 \pm 5,51$ & $70,83 \pm 5,32$ & $76,21 \pm 4,02$ & $69,58 \pm 3,57$ \\
\hline $\begin{array}{c}\text { Systolic blood pressure, } \\
\mathrm{mm} \mathrm{Hg}\end{array}$ & $111,67 \pm 5,65$ & $113,75 \pm 4,95$ & $112,08 \pm 5,09$ & $114,17 \pm 5,04$ \\
\hline \begin{tabular}{|c} 
Diastolic blood pressure, \\
$\mathrm{mm} \mathrm{Hg}$
\end{tabular} & $72,67 \pm 5,65$ & $73,75 \pm 4,95$ & $71,67 \pm 4,82$ & $74,17 \pm 5,04$ \\
\hline Vital_capacity, ml & $2756,25 \pm 129,64$ & $2956,25 \pm 126,24$ & $3131,25 \pm 182,26$ & $3314,58 \pm 174,75$ \\
\hline Sample Shtange, $p$ & $36,04 \pm 3,67$ & $41,33 \pm 2,24$ & $43,54 \pm 3,75$ & $46,17 \pm 3,02$ \\
\hline Gencha Sample, $p$ & $25,08 \pm 2,32$ & $30,92 \pm 2,50$ & $24,96 \pm 2,66$ & $34,83 \pm 3,17$ \\
\hline Dynamometer, kg & $32,88 \pm 6,33$ & $38 \pm 6,89$ & $41,25 \pm 6,89$ & $45,63 \pm 4,67$ \\
\hline Index of Ruffier c.u. & $9,00 \pm 2,90$ & $6,18 \pm 1,81$ & $10,55 \pm 2,89$ & $6,28 \pm 2,23$ \\
\hline Index of Robinson c.u. & $85,33 \pm 7,46$ & $80,65 \pm 7,80$ & $85,35 \pm 4,79$ & $79,40 \pm 4,69$ \\
\hline Index of Skibinsky c.u. & $13,07 \pm 1,89$ & $17,36 \pm 1,97$ & $17,94 \pm 2,14$ & $22,08 \pm 2,51$ \\
\hline
\end{tabular}

The indexes included in the method of assessment of physical fitness of young men also increased significantly (Table 2).

Table 2

\section{Dynamics of indices of physical fitness of boys 16-17 years, $(x \pm S)$}

(by the method of T.Y. Krutsevich, 2006)

\begin{tabular}{|c|c|c|c|c|c|}
\hline \multirow{2}{*}{ № } & \multirow{2}{*}{ Indexes } & \multicolumn{2}{|c|}{$\begin{array}{c}\text { Boys 16 years old. } \\
(\mathrm{n}=24)\end{array}$} & \multicolumn{2}{c|}{$\begin{array}{c}\text { Boys 17 years old. } \\
(\mathrm{n}=24)\end{array}$} \\
\cline { 3 - 6 } & & To & After & To & After \\
\cline { 2 - 6 } & & $x \pm S$ & $x \pm S$ & $x \pm S$ & $x \pm S$ \\
\hline 1. & Speed index & $3,96 \pm 0,21$ & $4,11 \pm 0,16$ & $3,74 \pm 0,14$ & $3,93 \pm 0,12$ \\
\hline 2. & Endurance index & $2,11 \pm 0,11$ & $2,22 \pm 0,11$ & $1,89 \pm 0,10$ & $2,01 \pm 0,09$ \\
\hline 3. & Speed-power index & $1,17 \pm 0,09$ & $1,23 \pm 0,07$ & $1,18 \pm 0,05$ & $1,24 \pm 0,04$ \\
\hline 4. & Power index & $54,69 \pm 15,20$ & $62,29 \pm 8,80$ & $59,85 \pm 12,69$ & $65,54 \pm 8,10$ \\
\hline 5. & Rufier index & $9,00 \pm 2,90$ & $6,18 \pm 1,81$ & $10,55 \pm 2,89$ & $6,28 \pm 2,23$ \\
\hline
\end{tabular}


Overall assessment of physical fitness among adolescents 16-17 years, presented by the following indicators (table 3 ).

Table

3

The dynamics of the level of physical fitness of boys 16-17 years

(by the method of T.Y. Krutsevich, 2006)

\begin{tabular}{|c|c|c|c|c|c|}
\hline \multirow{3}{*}{ № } & \multirow{3}{*}{ Level } & Boy: & rs old. & \multicolumn{2}{|c|}{$\begin{array}{c}\text { Boys } 17 \text { years old. } \\
(n=24)\end{array}$} \\
\hline & & \multicolumn{4}{|c|}{ 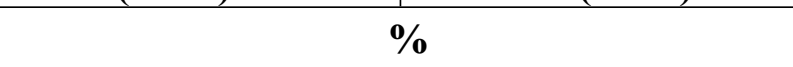 } \\
\hline & & To & After & To & After \\
\hline 1. & High & 0 & 20,83 & 0 & 0 \\
\hline 2. & Above average & 75 & 62,50 & 12,50 & 20,83 \\
\hline 3. & Average & 25 & 16,67 & 70,83 & 70,83 \\
\hline 4. & Below average & 0 & 0 & 16,67 & 8,33 \\
\hline 5. & Low & 0 & 0 & 0 & 0 \\
\hline
\end{tabular}

After twelve months of attending physical education classes with elements of aquarecreation, there were no students with low level of fitness. Positive changes among students of 17 years were observed at the level below average (results were decreased in 2 years and amounted to $8.33 \%$ ).

The boys in the 10th grade had positive changes at the above average and average levels. So, before the experiment, $75 \%$ of the boys got above average, and $25 \%$ - average. After applying the fitness program, the results of the average level decreased to $16.67 \%$, the level above the average amounted to $62.50 \%$, and accordingly students who received a high level $(20.83 \%)$ of the fitness indicator appeared.

The 17-year-old high school students had positive changes at below average and above average levels. According to the results presented in Table 3, the number of students who showed a level of fitness above the average was $20.83 \%$, comparing this result with the data obtained at the beginning of the pedagogical experiment, the result improved by almost 2 times $(12.50 \%)$. The below-average level has halved to $8.33 \%$ after, compared to $16.67 \%$ before. The average level (70.83\%) remained unchanged.

Positive dynamics were registered among the incidence rates of high school students who had a tendency for respiratory syndrome (33.28\% compared to $47.84 \%$ "before"). Young men began to complain less about chronic rhinitis, with only $12.48 \%$ of boys registered compared to $16.64 \%$ before. Also, high school students who had chronic tonsillitis were less likely to see a doctor ( $8.32 \%$ compared to $14.56 \%$ ). Unfortunately, such disorders that cause 
digestive diseases, enlargement of the thyroid gland I and II degree, pathology of the cardiovascular system have not undergone any significant changes.

Conducting physical and fitness classes with elements of aerobic exercise, such as aquarecreation, in combination with biological and biological means create favorable conditions for solving recreational problems in the process of leisure activities and help optimize the process of physical development.

A complex of training facilities should be used to increase the resistance of the youthful body. The resistance of body to cold can also be used in the course of aqua recreation. The main means of training were exercises that develop the aerobic capacity of the body. It should be noted that initially $30 \%$ of their total time was spent endurance training, but this percentage increased with each lesson due to the duration of rowing in the boat.

Conclusions. High level of physical fitness of high school students is revealed due to insufficient physical activity; unsatisfactory organization of physical education of student youth; negative attitude to physical education lessons; non-compliance with healthy lifestyle factors.

Despite the sufficiently high objectivity and effectiveness of current training programs for beginners, it is necessary to supplement them with a set of such pedagogical measures that are directly aimed at individualization of the training process, which we understand as the basic principle of physical load, by which each child's individuality is taken into account as a manifestation of his or her psychophysiological organization, that is, an acknowledgment of originality and uniqueness. The development and implementation of the training programs offered by us, take into account the principle of individual approach, ensured the maintenance of positive motivation to exercise the selected type of motor activity, promoted the harmonious development of young people and significantly improved their health.

\section{References}

1. American College of Sports Medicine (2011). Position stand. Quantity and quality of exercise for developing and maintaining cardiorespiratory, musculoskeletal, and neuromotor fitness in apparently healthy adults: guidance for prescribing exercise. Medicine and Science in Sports and Exercise, 43(7), 1334-1359.

2. Aranceta, J., Serra, L., Foz-Sala, M. \& Moreno, B. (2005). Prevalencia de obesidad en España. Medicina Clínica, 125, 460-466.

3. Balkó, Š., Balkó, I., Valter, L., Jelínek, M. (2017). Influence of physical activities on the posture in 10-11 year old schoolchildren. Journal of Physical Education and Sport, 17(1), 101-106. 
4. Bolotin, A., \& Bakayev, V. (2015). Structure and content of the educational technology of managing students' healthy life-style. Journal of Physical Education and Sport, 15(3). 362-364.

5. Brusseau, T. A., \& Hannon, J. C. (2015). Impacting Children's Health and Academic Performance through Comprehensive School Physical Activity Programming. International Electronic Journal of Elementary Education, 7(3), 441.

6. Brusseau, T. A., \& Kulinna, P. H. (2015). An examination of four traditional school physical activity models on children's step counts and MVPA. Research Quarterly for Exercise and Sport, 86(1), 88-93.

7. Brusseau, T. A., Hannon, J., \& Burns, R. (2016). The effect of a comprehensive school physical activity program on physical activity and health-related fitness in children from low-income families. Journal of Physical Activity and Health, 13(8), 888-894.

8. Burns, R. D., Brusseau, T. A., \& Fu, Y. (2017). Influence of Goal Setting on Physical Activity and Cardiorespiratory Endurance in Low-Income Children Enrolled in CSPAP Schools. American Journal of Health Education, 48(1), 32-40.

9. Duncan, J.S., Badland, H.M. \& Schofield, G. (2009). Combining GPS with heart rate monitoring to measure physical activity in children: a feasibility study. Journal of Sports Science and Medicine, 12(5), 583-585.

10. Durant, R.H., Baranowski, T., Davis, H., Rhodes, T., Thomson, W.O., Graves, K.A. \& Puhl, J. (1993). Reliability and variability of indicators of heart rate monitoring in children. Medicine and Science in Sports and Exercise, 25, 389-95.

11. Ekelund, U., Poortvliet, E., Yngve, A., Nilsson, A., Hurtig-Wennlof, A., \& Sjostrom, M. (2001). Heart rate as an indicator of physical activity intensity in adolescents.Medicine and Science in Sports and Exercise, 33(5), Supplement abstract 1406.

12. Pate, R.R., Flynn, J.I, Dowda, M (2016). Policies for promotion of physical activity and prevention of obesity in adolescence. Journal of Exercise Science\&Fitness, 14(2),pp.47-53.

\section{https://www.sciencedirect.com/science/article/pii/S1728869X1630154X}

13. WHO (2008). El aumento de la actividad física reduce el riesgo de enfermedades cardíacas y la diabetes.New York: World Health Organization. http://www.who.int/dietphysicalactivity/PAguide-2007- spanish.pdf

14. Andrieieva O.V (2014). Physical recreation of different population groups. K.: Polygraphservice: $280 \mathrm{~s}$. 
15. Kovaleva N.V, Andrieieva O.V (2011). Problems of activation of recreational and recreational activities of high school students in their free time. Science. magazine Nat. ped. to them. MP Dragomanov. 2011: [vol. 7, Avg. 15] P. 8-13.

16. Krutsevich T.Y., Vorobiov M.I, Bezverkhnya G.V. (2011). Control in the physical education of children, adolescents and young people: Educ. tool. K.: Olymp. Literature. 2011: $224 \mathrm{~s}$.

17. Skalski D., Lizakowski P., Nesterchuk N., Grygus I. (2018). Klasowe i warstwowe uwarunkowania uczestnictwa w sporcie a edukacja zdrowotna. Reabilitatsiini ta fizkulturnorekreatsiini aspekty rozvytku liudyny=Rehabilitation \& recreation. Rivne, 2018. 3. P. 132-138.

18. Skalski D., Formela M., Grygus I., Nesterchuk N., Tuz M., Kowalski D., Glazik R. (2018). Sposoby przeciwdziałania zachowaniu dewiacyjnemu w sporcie, a edukacja zdrowotna. Bezpieczeństwo i zdrowie. Wybrane zagadnienia. - Gdynia-Gdańsk-Starogard Gdański, 2018. S. 69-82. 